\title{
ARTICLE Preclinical evaluation of the kappa-opioid receptor antagonist CERC-501 as a candidate therapeutic for alcohol use disorders
}

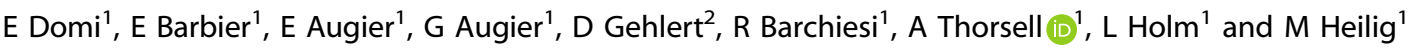

Prior work suggests a role of kappa-opioid signaling in the control of alcohol drinking, in particular when drinking is escalated due to alcohol-induced long-term neuroadaptations. Here, we examined the small molecule selective kappa antagonist CERC-501 in rat models of alcohol-related behaviors, with the objective to evaluate its potential as a candidate therapeutic for alcohol use disorders. We first tested the effect of CERC-501 on acute alcohol withdrawal-induced anxiety-like behavior. CERC-501 was then tested on basal as well as escalated alcohol self-administration induced by $20 \%$ alcohol intermittent access. Finally, we determined the effects of CERC-501 on relapse to alcohol seeking triggered by both stress and alcohol-associated cues. Control experiments were performed to confirm the specificity of CERC-501 effects on alcohol-related behaviors. CERC-501 reversed anxiety-like behavior induced by alcohol withdrawal. It did not affect basal alcohol self-administration but did dose-dependently suppress selfadministration that had escalated following long-term intermittent access to alcohol. CERC-501 blocked relapse to alcohol seeking induced by stress, but not when relapse-like behavior was triggered by alcohol-associated cues. The effects of CERC-501 were observed in the absence of sedative side effects and were not due to effects on alcohol metabolism. Thus, in a broad battery of preclinical alcohol models, CERC-501 has an activity profile characteristic of anti-stress compounds. Combined with its demonstrated preclinical and clinical safety profile, these data support clinical development of CERC-501 for alcohol use disorders, in particular for patients with negatively reinforced, stress-driven alcohol seeking and use.

Neuropsychopharmacology (2018) 43:1805-1812; https://doi.org/10.1038/s41386-018-0015-y

\section{INTRODUCTION}

Accumulating evidence suggests that kappa-opioid receptors (KORs) and their endogenous ligand dynorphin (DYN) play an important role in stress-reactivity and negative emotionality, including aspects of addictive disorders [1]. Expression of dynorphin mRNA and KORs is found in the hypothalamic paraventricular nucleus, amygdala, nucleus accumbens (NAc) and bed nucleus of stria terminalis, brain areas involved in control of mood and anxiety-related behaviors, as well as reward processes [2,3]. Initial findings of DYN involvement were in models of cocaine exposure and self-administration [4], but subsequent observations also suggest an involvement of the KOR/DYN system in aspects of alcohol reinforcement $[5,6]$.

Alcohol acutely induces the release of endogenous opioids such as beta-endorphin and enkephalin which are mainly involved in positive reinforcing effects of this drug, as well as the release of DYN, which contributes to the negatively reinforcing properties of alcohol [7, 8]. The increase of DYN in the NAc following administration of high alcohol doses was suggested to mediate the negative effects of alcohol [9]. For instance, intra-accumbal pharmacological activation of KORs reduces dopamine release in this region, while KOR blockade transiently increases extracellular levels of dopamine [10]. Accordingly, infusion of the KOR agonist, $\mathrm{U} 50488 \mathrm{H}$, into the NAc attenuates dopamine release and produces conditioned place aversion [11]. This points to a mechanism through which the DYN/KOR system may act as a mediator of alcohol's aversive properties.

In line with this hypothesis, increased KOR sensitivity together with a hypodopaminergic state of the NAc were associated with increased alcohol intake, anxiety-like and compulsive-like behaviors observed after chronic intermittent alcohol exposure [12]. Importantly, prolonged alcohol exposure in rats induces long-term neuroadaptations in the KOR/ DYN system which result in negative affective states $[13,14]$, as well as escalated alcohol consumption $[8,15,16]$.

Given the role of KORs in alcohol intake and negative affect, KOR antagonists represent a promising therapeutic strategy in alcohol addiction. However, KOR antagonists with properties making them suitable candidates for clinical development have been lacking. The prototypical KOR antagonist nor-binaltorphimine, (nor-BNI) suppresses increased alcohol self-administration and stress-induced alcohol seeking $[17,18]$ as well as stressinduced cocaine seeking behavior [19]. It is, however, not suitable for clinical development due to a slow onset of action and longlasting effects, potentially related to phosphorylation of c-Jun $\mathrm{N}$ terminal kinase (JNK; [20-22]).

We have also previously found that JDTic [23], a selective KOR antagonist with anxiolytic-like and antidepressant-like activity blocked withdrawal-induced anxiety-like behavior and reduced both alcohol self-administration and cue-induced reinstatement of

\footnotetext{
${ }^{1}$ Department of Clinical and Experimental Medicine, Center for Social and Affective Neuroscience, Linköping University, Linköping, Sweden and ${ }^{2}$ Cerecor, Baltimore, MD (DG) and Matrix Pharmaceutical Consulting, Boulder, CO, United States

Correspondence: M Heilig (markus.heilig@liu.se)
}

Received: 6 October 2017 Revised: 22 December 2017 Accepted: 9 January 2018

Published online: 5 February 2018 
alcohol seeking in rats [24]. Similarly to nor-BNI, JDTic has a complex pharmacology, which includes non-competitive effects likely to be mediated by modulation of JNK signaling [20]. The extent to which this would reduce it potential for clinical development will remain unknown, since JDTic was terminated from clinical development after Phase 1 due to cardiac toxicity [25].

CERC-501 (previously LY2456302) is a selective, orally available and centrally penetrant canonical KOR antagonist that displays reversible, competitive actions with a half-live that lends it suitable for clinical development [26]. Oral CERC-501 administration resulted in high occupancy of central KORs in vivo with an $\mathrm{ED}_{50}$ $=0.33 \mathrm{mg} / \mathrm{kg}$, while doses up $30 \mathrm{mg} / \mathrm{kg}$ did not result in measurable MOR or DOR occupancy [26]. CERC-501 has been found safe in Phase 1 in both healthy and cocaine-dependent subjects [27-29] and is available for clinical development.

Here, we evaluated CERC-501 in a battery of preclinical tests to assess its potential as a clinical candidate for alcohol addiction treatment. Specifically, we investigated the effect of CERC on the negative emotional state induced by alcohol withdrawal, on alcohol self-administration under both basal and escalated conditions, and on relapse to alcohol seeking triggered by alcohol-associated cues or stress. A range of control behaviors was also evaluated to determine the behavioral specificity of the effects observed in the alcohol models.

\section{MATERIALS AND METHODS}

\section{Drugs}

CERC-501 (CERECOR; Baltimore, USA) was dissolved in distilled water with the addition of $85 \%$ lactic acid and administered orally at the volume of $1 \mathrm{ml} / \mathrm{kg}$ [26]. Alcohol solutions were prepared volume/volume $(v / v)$ in tap water from $95 \%$ alcohol. Drugs were prepared freshly on the experimental day and rats were habituated to the route of the administration before the test.

\section{Animals}

Male Wistar rats (Charles River), weighing 250 to $300 \mathrm{~g}$ (7-9 weeks) at the beginning of the experiments were pair-housed with free access to tap water and food pellets. Rats were single housed during the two-bottle choice drinking paradigm. Animals were maintained in a temperature-controlled and humidity-controlled vivarium on a 12-h light/dark cycle (lights off at 7:00 a.m.) with water and food available ad libitum. Behavioral experiments were conducted during the dark phase of the cycle. Rats were handled three times before each experiment. All procedures were conducted in accordance with the National Committee for animal research in Sweden and the protocol was approved by the Local Ethics Committee for Animal Care and Use at Linköping University.

\section{Alcohol self-administration}

Operant training and testing was in thirty-two identical operant chambers (Med Associates Inc., St Albans, VT, USA; $30.5 \times 29.2 \times$ $24.1 \mathrm{~cm}$ ) housed in sound-attenuating cubicles. Each operant chamber was equipped with two retractable levers positioned laterally to a liquid cup receptacle.

Ninety-seven operant-naive and drug-naive rats were trained to self-administer $20 \%(\mathrm{v} / \mathrm{v})$ alcohol without sucrose/saccharin fading as described previously [30,31]. Rats were trained initially to lever press on a fixed ratio 1 (FR1) $5 \mathrm{~s}$ time-out (TO) schedule to selfadminister $20 \%$ alcohol during 30 min sessions. Two levers were extended to mark the onset of the session and to signal alcohol availability. Pressing once on the lever associated with alcohol (active) was reinforced by the delivery of a volume of $100 \mu \mathrm{l}$ of $20 \%$ alcohol in water in the adjacent drinking well and initiated a concomitant $5 \mathrm{~s}$ time-out period signaled by the illumination of the cue-light above the lever. Responses on the inactive lever and during the time-out period were recorded but had no programmed consequences. Sessions were conducted for 5 days a week until performance stabilized (defined as a minimum of 15 sessions and no change greater than $15 \%$ in the total number of reinforcers earned during the last three sessions). Once a stable self-administration baseline was reached, the sessions were conducted under a fixed ratio FR2 until a stable baseline of lever pressing was achieved (defined as a minimum of 15 sessions and no change greater than $15 \%$ in the total number of reinforcers earned during the last three sessions). Rats were then singlehoused and allowed continuous (CA) or intermittent (IAE) alcohol access under two-bottle free-choice conditions, in a randomized counterbalanced order based on the number of reinforcers earned in the last three training sessions. A shift between $20 \%$ ethanol drinking from a free-choice drinking model to an operant procedure has been previously described [32]. We modified this protocol by pre-training rats in the operant behavior prior the free-choice alcohol exposure. Rats that did not acquire the operant behavior drank low levels of ethanol in the IAE procedure. The opposite has previously also been found, such that rats consuming low amounts of alcohol will acquire lower rates of the operant behavior [32]. Animals that did not acquire the selfadministration procedure or earned less than 10 reinforcers during the session were excluded from the study [33].

Specific criteria for categorizing rats into "non-escalated" and "escalated" have for the most part not been provided in prior IAE studies. The fact that some rats do not escalate their drinking is an advantage of the procedure when the research question refers to individual differences [32, 34]. In our experiments, we used a formal cluster analysis approach, and found that $~ 70 \%$ of the rats on IAE escalated their operant self-administration, while only $11 \%$ of rats on CA did so. A schematic showing the training history of the rats and individual data of alcohol intake in CA and IAE groups is provided in Supplementary Information Figure S1.

\section{Reinstatement of alcohol seeking}

After the last alcohol self-administration session $(N=18)$, animals were subjected to 30-min extinction sessions over a minimum of 15 consecutive days for stress reinstatement test. A separate group of rats $(N=14)$ were used in a counterbalanced withinsubject design in the cue-induced reinstatement test. Responses on the lever activated the delivery mechanism but did not result in the delivery of alcohol. Rats were tested for reinstatement if they decreased their active lever presses to fewer than 15 during the last three stabilized sessions of extinction. After all rats achieved this criterion, the day after the last extinction session, they were pretreated with CERC-501 ( 0 or $10 \mathrm{mg} / \mathrm{kg}$, orally) and subjected to cue or stress reinstatement tests for alcohol. The $10 \mathrm{mg} / \mathrm{kg}$ dose was selected based on initial dose-ranging data, which showed that that this dose fully reversed acute withdrawal-induced anxiety-like behavior, without affecting locomotor activity. The footshock stress-induced reinstatement session followed $45 \mathrm{~min}$ after drug treatment. The footshock stress was a 15-min intermittent footshock stress $(0.6 \mathrm{~mA}$, train length $0.5 \mathrm{~s})$ administered via the grid floor of the chamber under a variable-interval $40 \mathrm{~s}$ schedule (interval range: 10-70 s). After termination of footshock, the levers were extended into the chambers, and responses were recorded for $30 \mathrm{~min}$. For evaluation of cueinduced reinstatement, the cue (light above the active lever) previously associated with availability of alcohol was presented the day of the experiment but not in the extinction phase. The experiment was carried out using a within-subject design for the reinstatement tests. Responding on the inactive lever was recorded throughout the experiment to monitor non-specific behavioral effects. Between each reinstatement test, animals performed at least 5 days of extinction sessions.

\section{Corticosterone and prolactin assay}

Blood samples were collected from the tail vein $12 \mathrm{~h}$ after the acute injection of the bolus dose $(3 \mathrm{~g} / \mathrm{kg})$ of $20 \% \mathrm{v} / \mathrm{v}$ alcohol. 
Samples were centrifuged for $10 \mathrm{~min}$ at $4{ }^{\circ} \mathrm{C}, 3000$ revolutions per minute, and plasma was extracted. A corticosterone enzyme immunoassay kit (Arbor Assays, Nordic Biosite $A B$ ) was used to analyze the samples for corticosterone. Detection levels for corticosterone were $7.8-1000 \mathrm{ng} / \mathrm{ml}$. A rat prolactin ELISA kit (Sigma-Aldrich corp. St. Louis, MO) was used for detecting prolactin levels in the same plasma samples. The detection limit of the assay was $0.41 \mathrm{ng} / \mathrm{ml}$. To minimize batch to batch variation, all samples were analyzed within a single assay.

\section{Statistics}

Alcohol escalation was defined by cluster analysis, using k-means clustering with 2 clusters to classify the animals irrespective of their alcohol access type. The effects of CERC-501 on escalated alcohol self-administration, reinstatement tests, blood alcohol levels, locomotor activity, corticosterone and prolactin analysis were analyzed by two-way ANOVA. The effects of CERC-501 on acute alcohol withdrawal and basal self-administration were analyzed by one-way ANOVA. Student's $t$ test was used to analyze the effect of CERC-501 on saccharin self-administration, loss of righting reflex and blood alcohol levels in the CA and IAE rats. Differences between control and experimental groups were considered significant if $p<0.05$. When appropriate, post hoc analyses were conducted using Newman-Keuls and Dunnett's tests.

Detailed information on alcohol withdrawal-induced anxiety; intermittent access to $20 \%$ alcohol (two-bottle free-choice procedure) and the control experiments are provided in Supplementary Methods section.

\section{RESULTS}

CERC-501 reverses acute alcohol withdrawal-induced anxiety-like behavior

The effect of CERC-501 on acute alcohol withdrawal was assessed in $N=71$ naive rats (for detailed method information, see Supplemental materials). In the absence of pretreatment with a
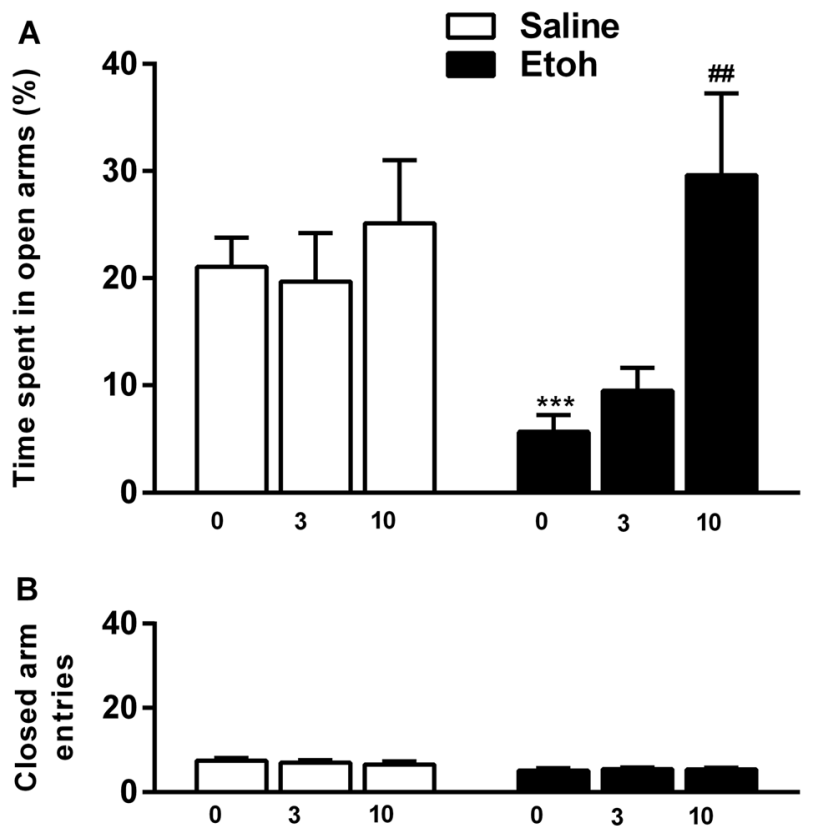

Fig. 1 CERC-501 reverses anxiogenic-like behavior induced by acute alcohol withdrawal. a Mean of time \% $( \pm$ SEM) spent in open arms of the EPM $(n=71)$. Alcohol withdrawal-induced anxiety-like behavior $\left({ }^{* *} p<0.001\right)$ was reversed by CERC-501 $(10 \mathrm{mg} / \mathrm{kg})$ treatment ${ }^{\# \#} p$ $<0.001$ compared to vehicle. b Mean of number of entries into the closed arms high bolus dose of alcohol, CERC-501 had no effect on anxiety-like behavior measured in the EPM (Fig. 1a, open bar $\left(F_{2,31}=0.39, p=\right.$ 0.7). In agreement with prior findings (e.g., ref. [35]), a marked anxiogenic-like effect was observed $12 \mathrm{~h}$ following administration of $3 \mathrm{~g} / \mathrm{kg}$ of alcohol, seen as a marked decrease in \%Open Time in the vehicle-treated groups, pretreated with an alcohol vs. a saline group $\left(t_{27}=4.97, p<0.001\right)$. Under these conditions, CERC-501 had a robust effect on anxiety-like behavior $\left(\mathrm{F}_{2,34}=8.2, p=0.001\right.$; $\eta^{2}=0.32$ ). Dunnet's post hoc test showed that CERC-501 at $10 \mathrm{mg} /$ $\mathrm{kg}$ fully reversed the suppression of \%Open Time due to alcohol withdrawal $(p<0.001)$, while $3 \mathrm{mg} / \mathrm{kg}$ did not differ from vehicle $(p=0.7)$. These effects were obtained in the absence of confounding locomotor effects, as the number of close arm entries, and established control for locomotion, was unaffected (Fig. $1 b, F_{2,34}=0.15, p=0.85$ ).

CERC-501 blocks alcohol withdrawal-induced prolactin, but not corticosterone response

Two-way ANOVA did not show any effect of alcohol pretreatment on prolactin levels $\left(\mathrm{F}_{1,28}=3.99, p=0.55\right)$, but did show a significant main effect of CERC-501 treatment $\left(\mathrm{F}_{1,28}=13.4, p=0.001 ; \eta^{2}=\right.$ 0.32 ) and a significant interaction between alcohol pretreatment $x$ CERC-501 treatment $\left(F_{1,28}=10.27, p=0.003 ; \eta^{2}=0.27\right)$. Specifically, Newman-Keuls post hoc test showed a significant increase of prolactin in the acute withdrawal group compared to saline ( $p$ $=0.001$ ), while CERC-501 significantly reduced prolactin levels only in the alcohol-treated group ( $p=0001$; Fig. 2a).
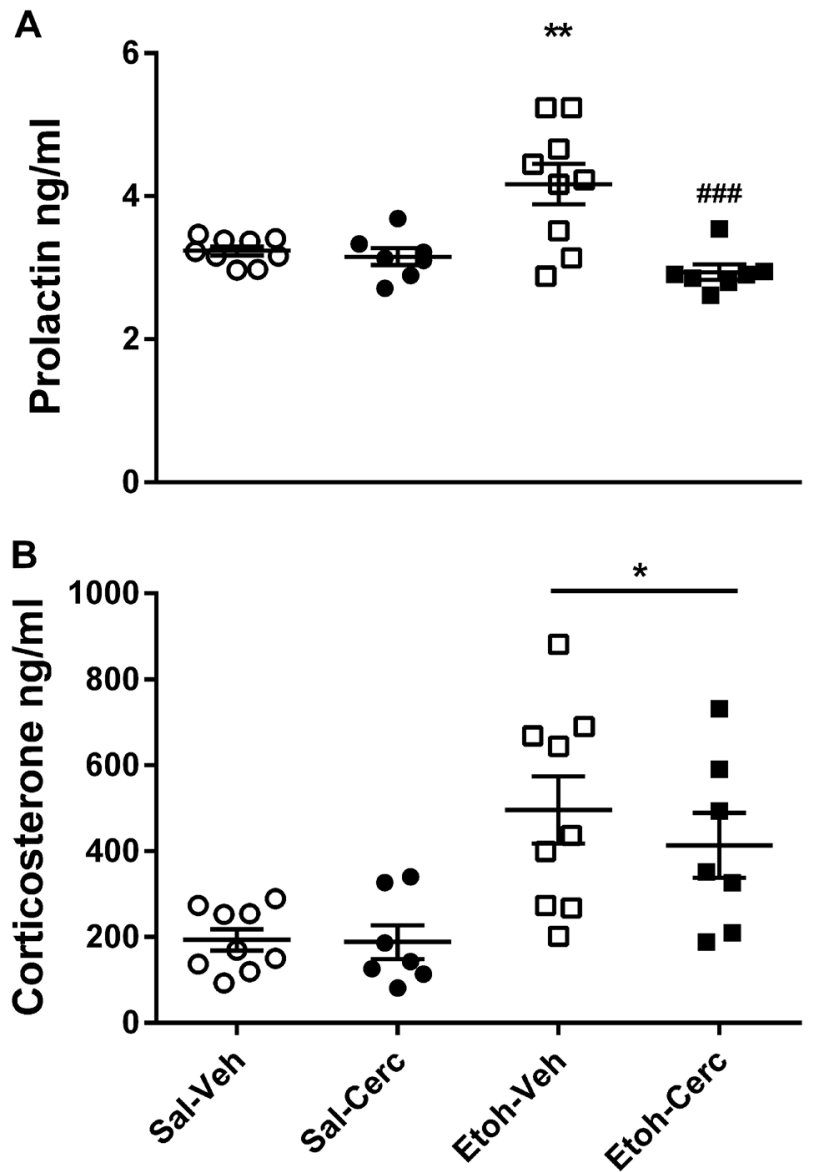

Fig. 2 a Acute alcohol withdrawal resulted in an increase of plasma prolactin levels $\left({ }^{* * *} p<0.001\right)$ that was abolished by pretreatment with CERC-501 (\#\#\#<0.001). b Acute alcohol withdrawal-induced a substantial increase of plasma corticosterone levels in both vehicle and CERC-501 treated rats $\left({ }^{* * *} p<0.001\right)$. Mean of prolactin and corticosterone levels $(\mathrm{ng} / \mathrm{ml})( \pm$ SEM) $(n=7 / 9$ per group) 
A
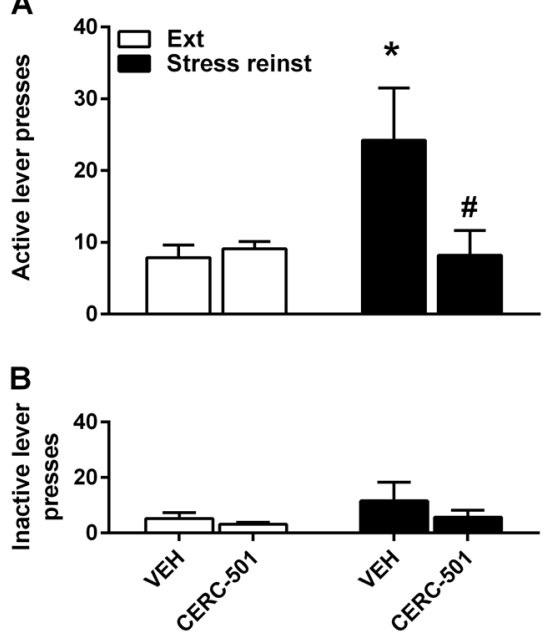

C
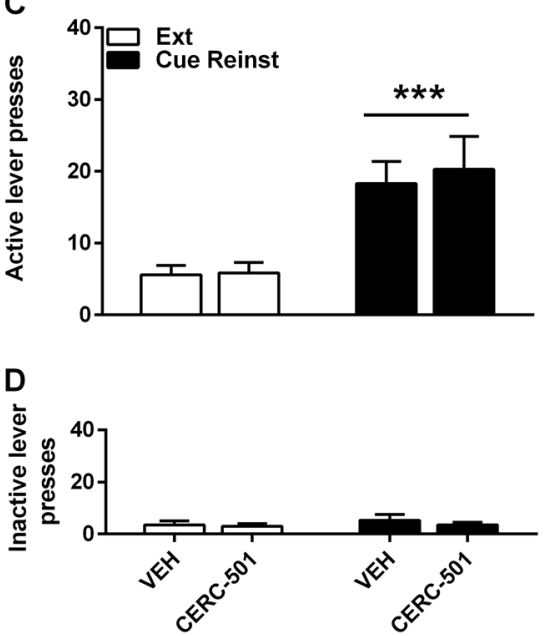

Fig. 3 CERC-501 suppresses stress-induced but not cue-induced reinstatement of alcohol seeking. a Mean of non-reinforced lever presses $( \pm$ SEM) during the 30-min test for stress-induced reinstatement of alcohol seeking following either vehicle or CERC-501 (10 mg/kg) treatment $(n=18)$. $\left({ }^{*} p<0.05\right)$ compared to extinction $\left({ }^{\#} p<0.05\right)$ compared to vehicle. b Mean of inactive lever presses $( \pm$ SEM) during the 30 min session. c Mean of non-reinforced lever presses $( \pm$ SEM) during the 30 min test for cue-induced reinstatement of alcohol seeking following either vehicle or CERC-501 treatment, $\left({ }^{* * *} p<0.001\right)$ compared to extinction. $\mathbf{d}$ Mean of inactive lever presses $( \pm$ SEM) during the 30 min test

ANOVA also showed a significant effect of alcohol pretreatment on the corticosterone response $\left(\mathrm{F}_{1,28}=19.4, p<0.0001 ; \eta^{2}=0.4\right)$, but did not show a significant main effect of CERC-501 treatment $\left(F_{1,28}=\right.$ $\left.0.5, p=0.47 ; \eta^{2}=0.02\right)$, or any interaction between alcohol pretreatment $\times$ CERC-501 treatment $\left(F_{1,28}=0.5, p=0.52\right)$. Newman-Keuls post hoc test showed a substantial increase of corticosterone in the acute withdrawal state in alcohol-treated rats compared to saline ( $p$ $=0.0002$; Fig. $2 b$ ), but no other significant group differences.

CERC-501 suppresses stress-induced relapse to alcohol seeking There was no difference in extinction responding rates between control and CERC-501-treated rats $(p=0.98)$ before the test. There were trend level main effects of test condition $\left(\mathrm{F}_{1,32}=3.4, p=0.07 ; \eta^{2}\right.$ $=0.43)$ and treatment $\left(F_{1,32}=3.4, p=0.09 ; \eta^{2}=0.40\right)$; and a significant interaction between stress condition and treatment $\left(\mathrm{F}_{1,32}=4.3, p=\right.$ $0.04 ; \eta^{2}=0.12$ ). Post hoc analysis showed that exposure to the footshock stressor elicited a significant reinstatement of alcohol seeking in the vehicle-treated rats $(p<0.05)$. This stress-induced reinstatement was blocked by CERC-501 treatment ( $p<0.05$; Fig. 3a).

There was no main effect or trend for main effect of test condition $\left(F_{1,32}=1.4, p=0.3\right)$, treatment $\left(F_{1,32}=1.1, p=0.29\right)$ or interaction between test condition $x$ treatment on the inactive lever presses $\left(F_{1,32}=0.24, p=0.62\right.$; Fig. 3b).

Cue-induce relapse to alcohol seeking is unaffected by CERC-501 Vehicle-treated and CERC-501-treated rats did not differ in their extinction responding rates before cue-induced reinstatement test $(p=0.6)$. ANOVA showed a robust reinstatement following exposure to the alcohol-associated cues $\left(F_{1,13}=60.65, p<0.001 ; \eta^{2}=0.82\right)$, but there was no main effect of CERC-501 treatment $\left(\mathrm{F}_{1,13}=0.03, p\right.$ $=0.86$ ), or interaction between reinstatement condition and drug $\left(F_{1,13}=0.32, p=0.58\right)$. Accordingly, post hoc analysis of test condition showed that reintroduction of the alcohol-associated cues led to a significant reinstatement of alcohol seeking in both vehicle-treated and CERC-treated rats $(p<0.001$; Fig. 3c). There was no effect of treatment $\left(\mathrm{F}_{1,13}=1.1, p=0.31\right)$, test condition $\left(\mathrm{F}_{1,13}=\right.$ $3.53, p=0.08)$ or interaction between these two factors $\left(F_{1,13}=0.7\right.$, $p=0.41$ ) on the inactive lever presses (Fig. 3d).

CERC-501 selectively suppresses escalated alcohol selfadministration

We used the established intermittent access procedure to induce escalation of alcohol self-administration; a separate group of rats on continuous access was included in this experiment for comparison. Because not all rats exposed to intermittent access escalate their alcohol intake, and some rats on continuous access may do so, we used k-means clustering with 2 clusters to classify animals, irrespective of their alcohol access type. The variables used in the clustering were 2-bottle free-choice (2BC) alcohol intake, relative alcohol preference, and operant self-administration; in each case, the variable was included as obtained at baseline, and also following the 12 weeks continuous or intermittent access, respectively.

In the intermittent access group, 15/22 animals were classified into Cluster 1 , while this only was the case for $2 / 19$ animals in the continuous access group. Conversely, $17 / 19$ rats in the continuous access group, but only $7 / 22$ rats in the intermittent access group were classified into Cluster 2 (Fisher's exact test, two-tailed: $p=$ 0.0003 ; Fig. 4a). The clusters did not differ on self-administration at baseline, prior to the respective access procedure (Cluster 1 vs. Cluster 2: $14.6 \pm 0.8$ vs. $14.7 \pm 1.8$ reinforcers/30 min session, mean $\pm \mathrm{SEM} ; \mathrm{F}_{1,39}=2.3, p=0.13$ ), but differed robustly when tested after intermittent or continuous access to alcohol, respectively (24.2 \pm 1.5 vs. $17.8 \pm 1.1 ; F_{1,39}=12.7, p=0.001$; Fig. 4b). Alcohol intake during self-administration expressed in $\mathrm{g} / \mathrm{kg}$ increased significantly in Cluster 1 vs. Cluster $2 \mathrm{~F}_{1,39}=33.6, p<0.001$ after $(2 \mathrm{BC})$ without showing differences before the procedure $\left(\mathrm{F}_{1,39}=2.8, p=\right.$ 0.1 ; Fig. 4c). On average, rats in Cluster 1 increased their selfadministration by $\sim 50 \%$. Therefore, Cluster 1 can appropriately be labeled "escalated". In contrast, rats in Cluster 2 did not show increased alcohol self-administration. Therefore, Cluster 2 can be labeled "non-escalated" (Fig. 4b). Inactive lever presses did not differ after the intermittent access for both clusters (Fig. 4d).

We then examined whether CERC-501 differentially influenced escalated, as opposed to basal (non-escalated) alcohol selfadministration. In order to assess a possible left-shift of the dose-response curve for CERC-501 in alcohol escalated compared to non-escalated rats, both doses of CERC-501 $(3,10 \mathrm{mg} / \mathrm{kg})$ were tested. Two-way ANOVA with cluster as a between-groups subject, and CERC-501 dose as a within-subject factor confirmed that the two clusters differed both in self-administration rates and in $\mathrm{g} / \mathrm{kg}$ of alcohol consumed (main effect of cluster: $\mathrm{F}_{1,39}=6.86, p=0.012$; $\mathrm{F}_{1,39}=7.38, p=0.001$ ), and that there was a significant overall effect of drug treatment (main effect of dose: $F_{2,78}=11.25, p=$ $\left.0.00005 ; F_{1,39}=7.02, p=0.0015\right)$. Most importantly, the analysis demonstrated that the two clusters responded differentially to the 
A

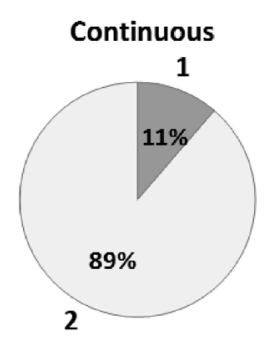

B

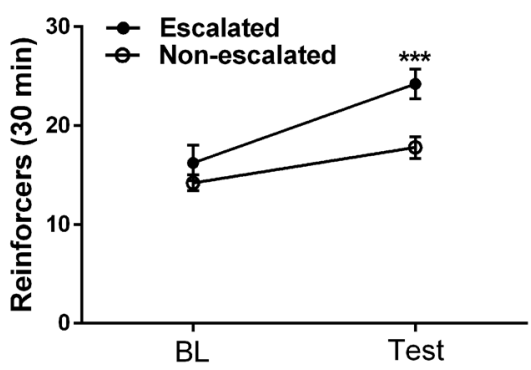

D

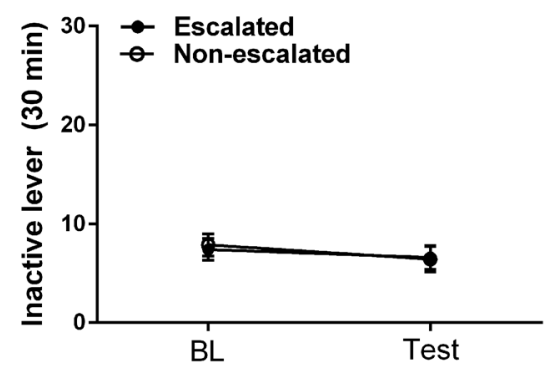

Fig. 4 Escalation of alcohol self-administration a Pie Charts of k-means of clusters 1 and 2 in continuous and intermittent group; $\mathbf{b}$ mean of reinforcers $( \pm$ SEM) earned during a 30-min FR2 self-administration session; c mean of alcohol $(\mathrm{g} / \mathrm{kg})( \pm$ SEM) achieved during a 30 min FR2 selfadministration session; $\mathbf{d}$ inactive lever presses of Non-escalated and Escalated rats before (BL) and after (IA2BC) procedure (TEST). ${ }^{* * *} p<$ $0.001)$

drug treatment (cluster $\times$ dose interaction: $F_{2,78}=7.07, p=0.002$; $\mathrm{F}_{2,78}=7.26, p=0.0012$ ).

Follow-up analyses restricted to the respective cluster showed that the drug effects determined in the complete model were entirely attributable to the escalated cluster. Specifically, within this cluster, CERC-501 robustly and dose-dependently suppressed operant alcohol self-administration, and accounted for a high proportion, or $52 \%$ of the variance in the number of reinforcers and alcohol intake (g/kg; Fig. 5a, b, filled circles; one-way ANOVA with dose as a within-subject factor; $F_{2,28}=15.4, p=0.00003$; partial $\eta^{2}=0.52$ and $F_{2,28}=16.1, p<0.0001, \eta^{2}=0.54$ ) respectively. Post hoc analysis (Newman-Keuls test) confirmed that both the 3 $\mathrm{mg} / \mathrm{kg}$ and the $10 \mathrm{mg} / \mathrm{kg}$ dose suppressed the number of reinforcers ( $3 \mathrm{mg} / \mathrm{kg}: p=0.03 ; 10 \mathrm{mg} / \mathrm{kg} p=0.0002$ ) and amount of alcohol intake (g/kg; $3 \mathrm{mg} / \mathrm{kg}: p=0.02 ; 10 \mathrm{mg} / \mathrm{kg}: p=0.0001)$ obtained within this group. Virtually identical results were obtained when restricting this analysis to members of the escalated cluster that had been exposed to the intermittent access, i.e., excluding the two rats that were classified as escalated despite exposure to continuous access (not shown). In contrast, in the non-escalated cluster, no significant effect, or a trend for an effect of CERC-501 was observed, neither for the number of reinforcers $\left(F_{2,46}=0.40, p=0.67\right)$, nor for alcohol intake $\left(\mathrm{g} / \mathrm{kg} ; \mathrm{F}_{2,46}\right.$ $=0.02, p=0.97$; Fig. 5, open circles). Very similar results were obtained when the latter analysis was restricted to non-escalated continuously exposed rats, or the minority of intermittently exposed rats that remained members of the non-escalated cluster (not shown).

Of note, CERC-501 administration brought self-administration rates in the escalated cluster very close to those in the nonescalated group. Furthermore, the complete lack of CERC-501 influence on self-administration rates in the non-escalated group provides a stringent control for behavioral specificity; specifically, it makes it unlikely that the effect in the escalated group was due to motor or other performance impairment to which selfadministration is sensitive.

Supporting this assumption, CERC-501 did not affect basal alcohol self-administration (Supplemental Information, Figure S2), saccharin self-administration, locomotor activity or alcohol metabolism (see for further detailed methods and results: Supplemental Information, Figure S3).

\section{DISCUSSION}

We found that CERC-501 fully reversed the anxiogenic-like effects of alcohol withdrawal and blocked stress-induced relapse-like behavior, without affecting cue-induced reinstatement of alcohol seeking. Furthermore, CERC-501 robustly and selectively suppressed escalated alcohol self-administration, while only marginally affecting basal rates of self-administration. This observation is of particular interest, because escalation of alcohol selfadministration is thought to reflect neuroadaptations that evolve over the course of developing alcohol addiction [14]. CERC-501 suppressed escalated alcohol self-administration and blocked stress-induced reinstatement, without affecting the sedative properties of alcohol, its metabolism or general locomotor activity, showing that these effects were behaviorally specific.

Acute administration of CERC-501 dose-dependently reduced withdrawal anxiety in a similar manner as previously shown for other prototypical KOR antagonists such as nor-BNI [36], JDTIc [24] and the novel relatively short-acting KOR antagonist LY2444296 which reduced anxiety-like behavior after chronic extended access of cocaine self-administration [37]. The anxiolytic-like effects of CERC-501 seem to occur through extra-hypothalamic mechanisms, as the increased corticosterone levels we observed during alcohol-induced withdrawal anxiety were not affected by CERC501 pretreatment. This is consistent with recent findings by Reed et al., who showed that chronic administration of CERC-501 in cocaine-dependent persons and healthy volunteers did not result in significant alteration of the neuroendocrine response [29].

While leaving HPA-axis responses to acute alcohol withdrawal unaffected, CERC-501 suppressed the increased prolactin plasma levels observed under this conditions, without affecting basal prolactin levels. This observation is consistent with previous findings showing an increase of prolactin in response to dynorphin or the KOR agonist U50 488, and a decrease in 

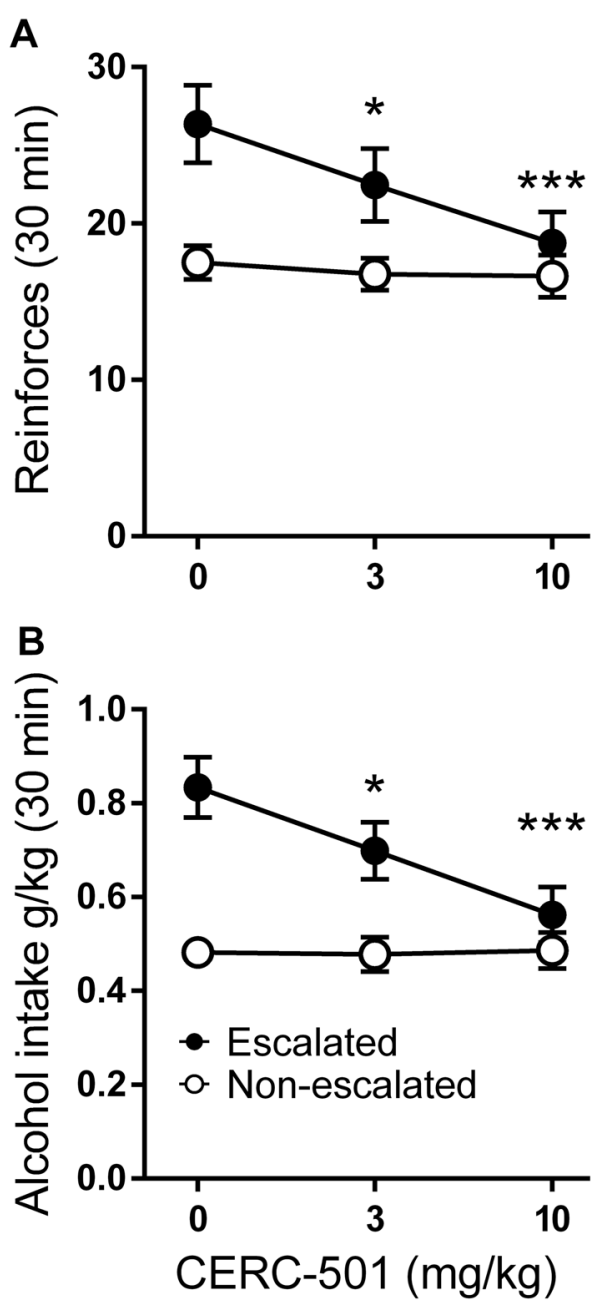

Fig. 5 CERC-501 selectively suppresses escalated alcohol selfadministration. a Mean reinforcers $( \pm$ SEM) earned during a 30 -min alcohol 20\% FR2 self-administration session and $\mathbf{b}$ Mean of alcohol $(\mathrm{g} / \mathrm{kg})( \pm \mathrm{SEM})$ in (non-escalated, $n=24$ vs. escalated, $n=17)$ following either vehicle or CERC-501 treatment $(0,3$, or $10 \mathrm{mg} / \mathrm{kg}$; $\left.{ }^{*} p<0.05\right)$; $\left({ }^{* * *} p<0.001\right)$

prolactin levels following administration of the KOR antagonist nor-BNI [38-40]. Elevation of prolactin levels have been found in male patients during alcohol withdrawal and are associated with the severity of alcohol dependence [41]. Prolactin is involved in stress responses, and has been proposed as a biological biomarker to predict the individual risk of alcohol withdrawal seizures [42]. From a clinical development perspective, the ability of CERC-501 to produce its anxiolytic-like effects while reducing prolactin, but in the absence of blocking HPA-axis function is therefore advantageous.

The effects of CERC-501 to suppress escalated alcohol selfadministration and stress-induced relapse appear to be highly specific behaviorally. Perhaps the most stringent control for nonspecific effects of CERC-501 was the test of cue-induced reinstatement, where the behavioral output is identical to the stress-induced relapse test, except for the stimulus used to trigger relapse-like behavior. A number of stressors, including intermittent footshock, induce an activation of the endogenous opioid systems [43]. A role of dynorphin and opioid receptors in stress-induced reinstatement of drug seeking has been shown previously. Specifically, systemic nor-BNI injections decreased stress-induced reinstatement of cocaine seeking, but were ineffective in mice lacking prodynorphin or KORs [44]. In another study, the long- lasting KOR antagonist, Arodyn suppressed stress-induced, but not cocaine priming-induced reinstatement of cocaine place preference [45].

Neuroadaptations within the DYN/KOR system occur during escalation of alcohol intake induced by a long period of repeated cycles of free-choice ethanol intake and withdrawal $[16,46]$. Negatively reinforcing properties of alcohol, together with the escalation of voluntary alcohol consumption, emerge as a result of neuroadaptations following a history of brain alcohol exposure [13]. Specifically, upregulation of the DYN/KOR system has been shown to contribute to escalated alcohol self-administration and the emergence of negative affective states during alcohol withdrawal [16]. Here, we modeled a heavy drinker phenotype by using the IAE procedure in which animals were intermittently exposed to alcohol for a relatively long period of time (i.e., 2 months; [32]), which is known to induce lasting neuroadaptations. Although this procedure results in escalation of average alcohol intake at a group level, individual variation is present, and some animals escalate their intake, while others do not. In the present study, CERC-501-suppressed alcohol drinking only in the escalated rats. A related compound, LY2456302 and other KOR antagonists have previously been shown to reduce voluntary drinking and alcohol self-administration in both male and female rats with escalated alcohol intake due to genetic selection $[47,48]$. In here, given the fact that $70-80 \%$ of treatment-seeking patients with alcohol use disorder are males we focused our study on male rats. Future studies will be necessary in order to determine whether CERC-501 has a similar effects on escalated alcohol intake in females.

Most of the studies have not found an effect of KOR antagonists on basal, non-escalated alcohol consumption $[49,8,18]$; one study even found an increase of basal alcohol intake by nor-BNI pretreatment [50]. Blocking the KOR system with a specific antagonist in alcohol dependent animals has been shown to attenuate escalated alcohol consumption during both acute and protracted abstinence [8, 15]. Mice lacking KORs or dynorphin exhibit reduced alcohol self-administration and do not increase alcohol intake following exposure to stress [51, 52]. Dysregulation in the DYN/KOR system has been implicated to be involved in increasing ethanol intake during the transition from alcohol use to dependence [53].

In interpreting our findings, it is important to consider whether the behavioral actions of CERC-501 we have observed might in part be mediated by MOR blockade. An ability of the prototypical KOR antagonist nor-BNI to also block MORs has been suggested in mice, although this observation was not replicated in rats $[54,55]$. CERC-501 has previously been shown to potently block KOR agonist-mediated analgesia and disrupt prepulse inhibition, without affecting MOR-agonist-mediated effects at $>30$-fold higher doses [48]. Moreover, the non-selective opioid antagonist naltrexone, which is preferentially active at MORs, selectively inhibits cue-induced but not stress-induced reinstatement [56]. In contrast, we found that CERC-501 blocked stress but not cueinduced relapse to alcohol seeking. Collectively, these observations argue against MOR activity of CERC-501 as a mechanism behind its effects on alcohol-related behaviors.

Thus, CERC-501 may act on neuroadaptation within DYN/KOR system induced by chronic alcohol exposure, without affecting its basal activity. Importantly, and in contrast to nor-BNI [10], CERC501 does not increase extracellular levels of dopamine in the nucleus accumbens [26], making it unlikely that it could have significant abuse liability. Taken together, our findings strongly support a potential for CERC-501 as a therapeutic in alcohol use disorders, in particular in anxious alcoholics where alcohol seeking and consumption are driven by negative reinforcement, or "reliefseeking".

DYN dysregulation is also implicated in the etiology of other stress-related psychiatric disorders, such as anxiety and depression 
[57]. Epidemiological studies show an extensive co-morbidity of these conditions with alcohol dependence [58]. Previously reported antidepressant-like effects of CERC-501 in preclinical models [26] suggest a potential utility of this molecule for the treatment of patients with this type of co-morbidity. If successful, this would address a major presently unmet medical need and KOR antagonists would represent a unique example in psychiatry where the therapeutic mechanism of a drug class is understood before it is shown to be efficacious in humans [59].

\section{ACKNOWLEDGMENTS}

We thank Dr. Ron Marcus and Drs. Natalie Farries of Cerecor INc., Baltimore, MD for their collaboration and CERC-501 supply.

\section{FUNDING}

This research was supported by funding from the Swedish Research Council and a grant from Cerecor Inc.

\section{ADDITIONAL INFORMATION}

Supplementary information accompanies this paper athttps://doi.org/10.1038/ s41386-018-0015-y.

Conflict of interest: The authors declare that they have no conflict of interest.

Publisher's note: Springer Nature remains neutral with regard to jurisdictional claims in published maps and institutional affiliations.

\section{REFERENCES}

1. Bruchas MR, Land BB, Chavkin C. The dynorphin/kappa opioid system as a modulator of stress-induced and pro-addictive behaviors. Brain Res. 2010;1314:44-55.

2. Crowley NA, Kash TL. Kappa opioid receptor signaling in the brain: circuitry and implications for treatment. Prog Neuropsychopharmacol Biol Psychiatry. 2015;62:51-60

3. Morris BJ, Haarmann I, Kempter B, Hollt V, Herz A. Localization of prodynorphin messenger rna in rat brain by in situ hybridization using a synthetic oligonucleotide probe. Neurosci Lett. 1986;69:104-8.

4. Hurd YL, Svensson P, Ponten M. The role of dopamine, dynorphin, and CART systems in the ventral striatum and amygdala in cocaine abuse. Ann N Y Acad Sci. 1999;877:499-506.

5. Heilig M, Schank JR. Kappa-opioid receptor antagonism: a mechanism for treatment of relief drinking? Biol Psychiatry. 2014;75:750-1.

6. Walker BM, Valdez GR, McLaughlin JP, Bakalkin G. Targeting dynorphin/kappa opioid receptor systems to treat alcohol abuse and dependence. Alcohol. 2012;46:359-70

7. Marinelli PW, Quirion R, Gianoulakis C. A microdialysis profile of beta-endorphin and catecholamines in the rat nucleus accumbens following alcohol administration. Psychopharmacology. 2003;169:60-67.

8. Walker BM, Koob GF. Pharmacological evidence for a motivational role of kappaopioid systems in ethanol dependence. Neuropsychopharmacology. 2008;33:643-52.

9. Marinelli PW, Bai L, Quirion R, Gianoulakis C. A microdialysis profile of Metenkephalin release in the rat nucleus accumbens following alcohol administration. Alcohol Clin Exp Res. 2005;29:1821-8.

10. Spanagel R, Herz A, Shippenberg TS. Opposing tonically active endogenous opioid systems modulate the mesolimbic dopaminergic pathway. Proc Natl Acad Sci USA. 1992;89:2046-50

11. Bals-Kubik R, Ableitner A, Herz A, Shippenberg TS. Neuroanatomical sites mediating the motivational effects of opioids as mapped by the conditioned place preference paradigm in rats. J Pharmacol Exp Ther. 1993;264:489-95.

12. Rose JH, Karkhanis AN, Chen R, Gioia D, Lopez MF, Becker HC et al. Supersensitive kappa opioid receptors promotes ethanol withdrawal-related behaviors and reduce dopamine signaling in the nucleus accumbens. Int J Neuropsychopharmacol. 2016;19:pyv127.

13. Heilig M, Egli M, Crabbe JC, Becker HC. Acute withdrawal, protracted abstinence and negative affect in alcoholism: are they linked? Addict Biol. 2010;15:169-84.

14. Meinhardt MW, Sommer WH. Postdependent state in rats as a model for medication development in alcoholism. Addict Biol. 2015;20:1-21.
15. Kissler JL, Sirohi S, Reis DJ, Jansen HT, Quock RM, Smith DG, et al. The one-two punch of alcoholism: role of central amygdala dynorphins/kappa-opioid receptors. Biol Psychiatry. 2014;75:774-82.

16. Berger AL, Williams AM, McGinnis MM, Walker BM. Affective cue-induced escalation of alcohol self-administration and increased $22-\mathrm{kHz}$ ultrasonic vocalizations during alcohol withdrawal: role of kappa-opioid receptors. Neuropsychopharmacology. 2013;38:647-54.

17. Harshberger E, Gilson EA, Gillett K, Stone JH, El Amrani L, Valdez GR. nor-BNI antagonism of kappa opioid agonist-induced reinstatement of ethanol-seeking behavior. J Addict. 2016;2016:1084235.

18. Walker BM, Zorrilla EP, Koob GF. Systemic kappa-opioid receptor antagonism by nor-binaltorphimine reduces dependence-induced excessive alcohol selfadministration in rats. Addict Biol. 2011;16:116-9.

19. Beardsley PM, Pollard GT, Howard JL, Carroll Fl. Effectiveness of analogs of the kappa opioid receptor antagonist (3R)-7-hydroxy-N-((1S)-1-\{[(3R,4R)-4-(3-hydroxyphenyl)-3,4-dimethyl-1-piperidinyl]methyl\}-2-methylpropyl)-1,2,3,4-tetrahydro3 -isoquinolinecarboxamide (JDTic) to reduce U50,488-induced diuresis and stress-induced cocaine reinstatement in rats. Psychopharmacology. 2010;210:189-98.

20. Bruchas MR, Yang T, Schreiber S, Defino M, Kwan SC, Li S, et al. Long-acting kappa opioid antagonists disrupt receptor signaling and produce noncompetitive effects by activating c-Jun N-terminal kinase. J Biol Chem. 2007;282:29803-11.

21. Butelman ER, Yuferov V, Kreek MJ. kappa-opioid receptor/dynorphin system: genetic and pharmacotherapeutic implications for addiction. Trends Neurosci. 2012;35:587-96.

22. Zhou L, Stahl EL, Lovell KM, Frankowski KJ, Prisinzano TE, Aube J, et al. Characterization of kappa opioid receptor mediated, dynorphin-stimulated [35S] GTPgammaS binding in mouse striatum for the evaluation of selective KOR ligands in an endogenous setting. Neuropharmacology. 2015;99:131-41.

23. Carroll I, Thomas JB, Dykstra LA, Granger AL, Allen RM, Howard JL, et al. Pharmacological properties of JDTic: a novel kappa-opioid receptor antagonist. Eur J Pharmacol. 2004;501:111-9.

24. Schank JR, Goldstein AL, Rowe KE, King CE, Marusich JA, Wiley JL, et al. The kappa opioid receptor antagonist JDTic attenuates alcohol seeking and withdrawal anxiety. Addict Biol. 2012;17:634-47.

25. Buda JJ, Carroll Fl, Kosten TR, Swearingen D, Walters BB. A double-blind, placebocontrolled trial to evaluate the safety, tolerability, and pharmacokinetics of single, escalating oral doses of JDTic. Neuropsychopharmacology. 2015;40:2059-65.

26. Rorick-Kehn LM, Witkin JM, Statnick MA, Eberle EL, McKinzie JH, Kahl SD, et al. LY2456302 is a novel, potent, orally-bioavailable small molecule kappa-selective antagonist with activity in animal models predictive of efficacy in mood and addictive disorders. Neuropharmacology. 2014;77:131-44.

27. Lowe SL, Wong CJ, Witcher J, Gonzales CR, Dickinson GL, Bell RL, et al. Safety, tolerability, and pharmacokinetic evaluation of single- and multiple-ascending doses of a novel kappa opioid receptor antagonist LY2456302 and drug interaction with ethanol in healthy subjects. J Clin Pharmacol. 2014;54:968-78.

28. Naganawa M, Dickinson GL, Zheng MQ, Henry S, Vandenhende F, Witcher J, et al. Receptor occupancy of the kappa-opioid antagonist LY2456302 measured with positron emission tomography and the novel radiotracer 11C-LY2795050. J Pharmacol Exp Ther. 2016;356:260-6.

29. Reed B, Butelman ER, Fry R, Kimani R, Kreek MJ. Repeated administration of opra kappa (LY2456302), a novel, short-acting, selective KOP-r antagonist, in persons with and without cocaine dependence. Neuropsychopharmacology. 2017:43:739-750.

30. Augier E, Dulman RS, Singley E, Heilig M. A method for evaluating the reinforcing properties of ethanol in rats without water deprivation, saccharin fading or extended access training. J Vis Exp. 2017.

31. Augier E, Flanigan M, Dulman RS, Pincus A, Schank JR, Rice KC, et al. Wistar rats acquire and maintain self-administration of $20 \%$ ethanol without water deprivation, saccharin/sucrose fading, or extended access training. Psychopharmacology. 2014;231:4561-8.

32. Carnicella S, Ron D, Barak S. Intermittent ethanol access schedule in rats as a preclinical model of alcohol abuse. Alcohol. 2014;48:243-52.

33. Carnicella S, Yowell QV, Ron D. Regulation of operant oral ethanol self-administration: a dose-response curve study in rats. Alcohol Clin Exp Res. 2011;35:116-25.

34. Simms JA, Steensland P, Medina B, Abernathy KE, Chandler LJ, Wise R, et al. Intermittent access to $20 \%$ ethanol induces high ethanol consumption in LongEvans and Wistar rats. Alcohol Clin Exp Res. 2008;32:1816-23.

35. Gehlert DR, Cippitelli A, Thorsell A, Le AD, Hipskind PA, Hamdouchi C, et al. 3-(4Chloro-2-morpholin-4-yl-thiazol-5-yl)-8-(1-ethylpropyl)-2,6-dimethyl-imidazo [1,2b]pyridazine: a novel brain-penetrant, orally available corticotropin-releasing factor receptor 1 antagonist with efficacy in animal models of alcoholism. J Neurosci. 2007;27:2718-26. 
36. Tejeda HA, Hanks AN, Scott L, Mejias-Aponte C, Hughes ZA, O'Donnell P. Prefrontal cortical kappa opioid receptors attenuate responses to amygdala inputs. Neuropsychopharmacology. 2015;40:2856-64.

37. Valenza M, Butelman ER, Kreek MJ. "Effects of the novel relatively short-acting kappa opioid receptor antagonist LY2444296 in behaviors observed after chronic extended-access cocaine self-administration in rats". Psychopharmacology. 2017;234:2219-31.

38. Andrews ZB, Grattan DR. Opioid receptor subtypes involved in the regulation of prolactin secretion during pregnancy and lactation. J Neuroendocrinol. 2003;15:227-36.

39. Kreek MJ, Schluger J, Borg L, Gunduz M, Ho A. Dynorphin A1-13 causes elevation of serum levels of prolactin through an opioid receptor mechanism in humans: gender differences and implications for modulation of dopaminergic tone in the treatment of addictions. J Pharmacol Exp Ther. 1999;288:260-9.

40. Krulich L, Koenig Jl, Conway S, McCann SM, Mayfield MA. Opioid kappa receptors and the secretion of prolactin (PRL) and growth hormone $(\mathrm{GH})$ in the rat. II. GH and PRL release-inhibiting effects of the opioid kappa receptor agonists bremazocine and U-50,488. Neuroendocrinology. 1986;42:82-87.

41. Wilhelm J, Heberlein A, Karagulle D, Groschl M, Kornhuber J, Riera R, et al. Prolactin serum levels during alcohol withdrawal are associated with the severity of alcohol dependence and withdrawal symptoms. Alcohol Clin Exp Res. 2011;35:235-9.

42. Hillemacher T, Frieling $\mathrm{H}$, Bayerlein $\mathrm{K}$, Wilhelm J, Kornhuber J, Bleich S. Biological markers to predict previous alcohol withdrawal seizures: a risk assessment. J Neural Transm. 2007;114:151-4.

43. Akil H, Watson SJ, Young E, Lewis ME, Khachaturian H, Walker JM. Endogenous opioids: biology and function. Annu Rev Neurosci. 1984;7:223-55.

44. Redila VA, Chavkin C. Stress-induced reinstatement of cocaine seeking is mediated by the kappa opioid system. Psychopharmacology. 2008;200:59-70.

45. Carey AN, Borozny K, Aldrich JV, McLaughlin JP. Reinstatement of cocaine placeconditioning prevented by the peptide kappa-opioid receptor antagonist arodyn. Eur J Pharmacol. 2007;569:84-89.

46. Lindholm S, Werme M, Brene S, Franck J. The selective kappa-opioid receptor agonist $\mathrm{U} 50,488 \mathrm{H}$ attenuates voluntary ethanol intake in the rat. Behav Brain Res. 2001;120:137-46.

47. Cashman JR, Azar MR. Potent inhibition of alcohol self-administration in alcoholpreferring rats by a kappa-opioid receptor antagonist. J Pharmacol Exp Ther. 2014;350:171-80.
48. Rorick-Kehn LM, Witkin JM, Statnick MA, Eberle EL, McKinzie JH, Kahl SD, et al. LY2456302 is a novel, potent, orally-bioavailable small molecule kappa-selective antagonist with activity in animal models predictive of efficacy in mood and addictive disorders. Neuropharmacology. 2014;77:131-44.

49. Doyon WM, Howard EC, Shippenberg TS, Gonzales RA. Kappa-opioid receptor modulation of accumbal dopamine concentration during operant ethanol selfadministration. Neuropharmacology. 2006;51:487-96.

50. Mitchell JM, Liang MT, Fields HL. A single injection of the kappa opioid antagonist norbinaltorphimine increases ethanol consumption in rats. Psychopharmacol (Berl). 2005;182:384-92.

51. Kovacs KM, Szakall I, O'Brien D, Wang R, Vinod KY, Saito M, et al. Decreased oral self-administration of alcohol in kappa-opioid receptor knock-out mice. Alcohol Clin Exp Res. 2005;29:730-8.

52. Racz I, Markert A, Mauer D, Stoffel-Wagner B, Zimmer A. Long-term ethanol effects on acute stress responses: modulation by dynorphin. Addict Biol. 2013;18:678-88.

53. Siciliano CA, Calipari ES, Cuzon Carlson VC, Helms CM, Lovinger DM, Grant KA, et al. Voluntary ethanol intake predicts kappa-opioid receptor supersensitivity and regionally distinct dopaminergic adaptations in macaques. J Neurosci. 2015;35:5959-68.

54. Picker MJ, Mathewson C, Allen RM. Opioids and rate of positively reinforced behavior: III. Antagonism by the long-lasting kappa antagonist norbinaltorphimine. Behav Pharmacol. 1996;7:495-504.

55. Broadbear JH, Negus SS, Butelman ER, de Costa BR, Woods JH. Differential effects of systemically administered nor-binaltorphimine (nor-BNI) on kappa-opioid agonists in the mouse writhing assay. Psychopharmacol (Berl). 1994;115:311-9.

56. Liu X, Weiss F. Additive effect of stress and drug cues on reinstatement of ethanol seeking: exacerbation by history of dependence and role of concurrent activation of corticotropin-releasing factor and opioid mechanisms. J Neurosci. 2002;22:7856-61.

57. Knoll AT, Carlezon WA Jr.. Dynorphin, stress, and depression. Brain Res. 2010;1314:56-73.

58. Grant BF, Stinson FS, Dawson DA, Chou SP, Dufour MC, Compton W, et al. Prevalence and co-occurrence of substance use disorders and independent mood and anxiety disorders: results from the National Epidemiologic Survey on Alcohol and Related Conditions. Arch Gen Psychiatry. 2004;61:807-16.

59. Carlezon WA Jr., Krystal AD. Kappa-opioid antagonists for psychiatric disorders: from bench to clinical trials. Depress Anxiety. 2016;33:895-906. 